\title{
O TRABALHO DA ENFERMEIRA: NEM PÚBLICO, NEM PRIVADO FEMININO, DOMÉSTICO E DESVALORIZADO*
}

\author{
Maria Julia Marques Lopes**
}

\begin{abstract}
RESUMO - Propōose a analisar criticamente a história da Enfermagem em confronto com a história da subordinação da mulher na perspectiva da sociedade patriarcal, no sentido de captar como se define e se organiza um "profissão feminina". A exploração capitalista do trabalho da mulher também está posta, no sentido de entender a realidade da categoria profissional $\Theta$, assim, visualizar caminhos que apontem para a construção de uma prática autônoma e competente.
\end{abstract}

ABSTRACT - The purpose of this study is to make a critical analysis of the history of Nursing facing the history of women's subjection in the view of patriarchal society, so that one can understand how a"female profession" can be defined and organized. The capitalist exploitation of women's work is also presented, in order to facilitate the understanding of this professional category, with a view to developing an autonomous and qualified practice.

\section{INTRODUÇÃO}

Este estudo tem o propósito de analisar a enfermagem enquanto "profissão feminina". Uma abordagem histórica permite visualizar como se tem dado o ingresso da mulher na força de trabalho público, os redutos em que são incorporados e, mesmo, a construção ideológica de suas aspiraçð̃es.

Nesse sentido parte-se para analisar como se definiu historicamente a mulher enquanto sujeito dominado, a legitimação da opressão culminando com sua marginalização enquanto cidadã. Para tanto, discute a construção cultural dominada do gênero feminino

A questão da divisão sexual do trabalho enquanto processo histórico definido por uma própria e implicita hierarquia sexual, é assunto tratado. A discussão se processa a nível da sexualização das ocupaçס̄es e da reorganização capitalista do trabalho da mulher.

Coloca a ação concreta da mulher a partir de sua identidade construida de forma dominada e oprimida. Discute a marginalização da mulher da vida política e a informalidade do seu poder destinado ao "consumo interno". Demarcado assim os três processos de: dominação, opressão e marginalização, passa-se a analisar a situação concreta de profissão de enfermeira e seu exercício profissional. Com isso interrelaciona-se os rumos do debate e das questões teóricas até então postas. A intenção é de propor uma análise crítica capaz de vincular reflexão e prática através de histórias de vida, entrevistas e depoimentos, e até mesmo de uma perspectia antropológica aprofundando a compreensão de como as enfermeiras respondem aos despojamentos e à dupla dominação.
Buscando uma conclusão tece-se algumas consideraçōes que afirma-se de caráter indicativo, merecedoras de ulterior investigação em muitos pontos.

Por último, ressalta-se a opçāo em utilizar a designação de gênero feminino à categoria, referindo-se à enfermeira e não ao enfermeiro, forma masculina, comumente usada. Essa opsão prende-se ao fato de acreditar na necessidade de tratar a dualidade dos sexos e não de omitt-la numa designação genética. Concretamente alicerça-se esta posição, em uma abrangência ampla enquanto questão teórica e no limite mais específico do contigente eminentemente feminino (96\%) da categoria das enfermeiras com formação universitárias no Pás.

\section{A DOMINAÇÃO ...e a definição de sujeito.}

O ponto de partida da reflexão é a existência concreta da dominação entre o sexo. Não se pretender discutir as rafzes dessa dominação mas, sim, avaliar algumas de suas formas de expressão e legitimaçāo. Convém ressaltar como a relação de dominação homem-mulher enquanto desigualdade de poder, se construiu a partir de um discurso de cunho biológico, histórico e psicológico que fundamentou ou deu legitimidade a essa dominação. A sociedade patriarcal propōe concretamente o aparato que discrimina, limita e restringe a liberdade da mulher.

Para STOLCKE et alii (1980, p. 89), "'na sociedade de classes, o processo de divisāo sexual do trabalho - a domesticação das mulheres - é, em última instância, produto do controle dos homens sobre a

* Dissertação para Obtenção do Título de Mestre em Sociologia na PUC/RS - Resumo

** Enfermeira COREn/RS 15640, Prof? da Universidade do Rio Grande do Sul, Mestre em Sociologia da Sociedade Industrial 
sexualidade e a capacidade reprodutiva das mulheres a fim de assegurar a reprodução do acesso desigual aos meios de produção".

A contradição básica que se discute é a de como se articulam esses mecanismos de controle para manter a separação entre o público e o privado, o trabalho social produtivo e o doméstico, a cultura e a natureza, o masculino e o feminino enquanto organização dos sujeitos sociais. Utiliza-se, aqui, o público e o doméstico como definidores ou abrangências de todos esses confrontos, não apenas reduzindo, por exemplo, doméstico ao trabalho do lar.

Nessa perspectiva, passa-se a analisar a relação de inferioridade que se estabelece nesse confronto, tendo consciência de que o doméstico não representa intrinsecamente inferioridade como se quer crer, mas que a sua manutenção enquanto inferior é uma necessidade para o controle e a perpetuação da subordinação da mulher.

As contribuições femininas à relaçāo extra-domésticas raramente são explícitas. A elas é dado um papel social e uma definição em virtude tanto de sua idade quanto de seu relacionamento com os homens. Portanto, as mulheres são concebidas, quase exclusivamente como irmãs, esposas e mães.

Assim percebido, fica nf́tida a associação ou o direcionamento no âmbito extra-doméstico das mulheres, a determinadas profissōes. Ser parteira, prof essora ou enfermeira não significa apenas uma escolha mas, uma oportunidade que a mulher encontra para por em prática atitudes que aprendeu desde o berço: servilismo, bondade, paciência, dedicação e carinho.

" O preparo da alimentação, para a recuperação de homens e mulheres que trabalham; o cuidado de crianças, velhos e doentes; higiene, enfermagem, costura, foram encargos domésticos quase totalmente assumidos pelas mulheres, que os continuam executando quando desenvolvem outra atividade produtiva". (CARRION, citada por ALBORNOZ, 1985, p.6)

Assim, o trabalho feminino tem hoje uma dupla subalternidade em casa e fora dela; é mais barato, igualmente apto, menos reinvindicativo e igualmente submisso.

Toda a mística com sua influência emocional nos papéis domésticados da mulher, em detrimento de sua participação na sociedade mais ampla, tem como objetivo conseguir sua adesão às normas tradicionais. Estas normas têm tal poder persuasivo, que mesmo as mulheres que a elas nāo aderem, sentem-se na obrigação de fazer crer que o fazem. Ao se identificar deste modo "como prendas domésticas" as mulheres preenchem expectativas que elas sentem existirem para si.

Conforme STOLCKE citada por COSTA (1984, p. 148), "apesar da incorporação no trabalho assalariado, a responsabilidade principal das mulheres continua sendo ter filhos e criá-los, e as tarefas rela- cionadas a isto. De fato, há uma avaliação diferente para o trabalho assalariado de homens e mulheres: os homens trabalham para manter a famflia, as mulheres para ajudar e há uma motivação diferente para trabalhar por um salário: as mulheres trabalham porque a necessidade as obriga quando o salário do marido é insuficiente, os homens porque são homens. $\mathrm{O}$ trabalho assalariado das mulheres é considerado como subsídio para manutenção da famflia. Essa definição, principalmente doméstica, af eta tanto o desempenho das mulheres no trabalho, quanto sua remuneração".

As questões até aqui abordadas referem-se ao espaço reservado, e, portanto, socialmente aceito, via especificidade histórica de gênero ou seja as definiçōes do "específico feminino". A partir dessa construção "feminina" de sujeito social parte-se para analisar como se organizam esses sujeitos sob o modo de produção capitalista que, se não engendrou a dominação entre os sexos, legitima e utiliza-se da manutenção da desigualdade em todos os nfveis para consolidar seus propossitos.

\section{A OPRESSÃO ...e a organizaçăo dos Sujeitos}

A questão mais objetiva da discriminação que concretamente se percebe no mercado de trabalho é a divisão sexual do trabalho.

A assimilação da mulher no campo do trabalho público tem se dado de forma discriminada a nivel de tarefas, de salários e da possibilidade de ascenção. A dupla jornada (a permanencia do trabalho doméstico como atribuição primária e mais importante), a definição enquanto mãe e esposa, o caráter subsidiário emprestado ao seu desempenho na esfera pública culminando com a marginalização da vida política, sāo as evidências de quão desigual foi e continua sendo a participação das mulheres na esfera do trabalho.

Uma perspectiva se impōe: a de que o processo de dominação está na esfera mais ampla do que apenas a do trabalho na esfera produtiva ou pública. $O$ trabalho remunerado da mulher trabalhadora é compatibilizado com sua condição de subordinada e não mudou sua atribuição primária ao trabalho domestico.

Nessa perspectiva, a profissionalização da mulher tem refletido sua condição subalterna enquanto indivíduo, na constatação de que sua assimilação ou mesmo sua escolha profissional deliberada se dá em áreas socialmente desprestigiadas ou desprezadas pelo sexo oposto. Identificam-se assim como "femininos"'os ramos do emprego doméstico," da saúde, das funções burocráticas, de escritório e mais recentemente o comércio.

Assim, o Capital e o Estado reorganizam a divisão sexual do trabalho utilizando maciçamente mão-de-obra feminina em atividades antes do âmbito doméstico. Por exemplo, opera a cisão entre a prá- 
tica religiosa e a técnico-profissional na área de saúde, mantendo-se inalterado o prestígio social da mulher que agora é trabalhadora assalariada.

O capitalismo processou inúmeras mudanças, mas conservou o que dá suporte a estrutura das relações sociais de dominação. A recriação das condiçōes subordinadas do trabalho da mulher tem sido um dos suportes da manutenção das relações de produção.

\section{A MARGINALIZAÇÃO ...da definiçăo à organizaçăo a açăo política}

"A mulher tem o direito de subir ao cadafalso; ela tem da mesma forma o direito de subir na tribuna."

Como diz CARRION, citada por ALBORNOZ (1985, p.83), o século XIX assiste o auge da ideologia da "mulher dentro de casa". O capitalismo industrial utiliza-se da mulher na acumulação de base com o trabalho doméstico gratuito, como mão-de-obra de reserva e barata. Cria-se então a ambigüidade onde se processa a separação pelo modo de produção vigente entre o lugar de produção e o lugar de reprodução biológica, necessidade do momento histórico. Como compatibilizar mulher na fábrica produzindo e em casa reproduzindo?

A reflexão traz a perspectiva do entendimento de como os acenos do mundo público se dão corroborando a dominação do mundo privado. Assim, a propria incorporação da mulher no mercado de trabalho reflete a mesma imagem do que dela se espera no âmbito privado. Nessas bases se estabelecem as tarefas que são preferentemente de mulheres, como as de enfermeiras, por exemplo. De onde se pergunta qual o componente "feminino" e qual a expressão "feminina" dessa tarefa? Sobre que bases senão da ideologia sexista, se assentam esses pressupostos?

Cabe refletir sobre o tema a luz dos protestos emitidos pelas feministas já no século XVI contra a "morte civil" da mulher na famflia e sua exclusão das funções produtivas e políticas.

No campo da participação política, é evidente a falta de participação da mulher de forma engajada e ativa. A participação quando existe, se dá com um desempenho acessório tanto no interior dos partidos quanto nos grupos de direita ou esquerda. "Excepcionalmente, as mulheres ocupam cargos de direção e responsabilidade, e quando chegam a essas posições o fazem com qualquer homem que desconhece a problemática social da mulher" (VELAZQUEZ, 1985, p.99).

Ainda, as ocupaçōes maciçamente femininas apresentam uma enorme fragilidade na luta por melhores condições de trabalho e de vida, sendo de ordinário extremamente baixo o indice de sindicalização de mulheres. Um exemplo disso estáp na participação das enfermeiras enquanto associadas ao seu sindicato no Rio Grande do Sul, o percentual de sin- dicalizadas é de apenas $30 \%$.

Nessa linha, depoimentos de enfermeiras atestam: "a gente trabalha fora,falta tempo para cuidar do marido, dos filhos, as reuniōes das entidades são geralmente à noite, horário que se quer e se precisa ficar em casa, lavando, arrumando etc... Tambem apontam fatores de omissāo ligados a: alienação, falta de tradição política da mulher, elitismo, submissảo, falta de profissionalismo, de consciência de classe (enfermeira não se considera trabalhadora), acomodação, ignorância (grifos da autora).

Um aspecto claro na enfermagem está não só na argumentação via articulação da vida privada com a pública, no papel internalizado da prioridade do papel na reprodução e no mundo doméstico, como também parece ser imutável para a vida de enfermeira. De tal forma, o componente ideológico do mito da mulher-mãe-esposa está presente no dia-a-dia da enfermeira que é usado para o obscurecimento das outras dimensões da mulher enquanto profissional e cidadã.

Concretamente, as associações representativas refletem o espaço reservado à mulher. É crucial no entanto que ao se avaliar essa realidade se proponha a reflexão da via política enquanto transformação dessa realidade. Se a realidade dos trabalhadores e especificamente das trabalhadoras é de alienação em relação a sua situação enquanto classe e gênero e das perspectivas de emancipação que dispõe, que caminhos apontar?

Com o entendimento de que, o âmbito da participação sindical, por exemplo, representa uma instância capaz de construir e consolidar unificadamente a consciência e as conquistas da classe trabalhadora, tem-se a dimensão de sua perspectiva transformadora da realidade dessa classe. Assim, investir na perspectiva de construção solidária de uma prática independentizante com esse tipo de entidade pode representar para as trabalhadoras de enfermagem, merece reflexão.

\section{A CATEGORIA DE ENFERMEIRAS ...na sexualização das ocupaçర̃es - o contexto da enfermagem}

A enfermagem brasileira se profissionaliza mantendo os padrōes da divisão sexual do trabalho e as características religiosas, expressas por princípios éticos e deontologicos, rígidas normas de conduta, disciplina e empirismo preservados no contingente elevado de atendentes que executam as tarefas de menor prestrgio, e que então servem à disciplina do capital.

Para DONNANGELO (1976,P.30), o cuidado médico se generaliza amplamente como resposta quer à necessidacie de reprodução da força de trabalho frente ao processo de produção económica quer a momentos particulares de desenvolvimento, a nivel político dos antagonismos de classe. $O$ que se verifica paralelamente é de um lado a seleção de grupos 
sociais a serem inicorporados ao cuidados médico conforme o seu significado para o processo económico e político, e de outro lado, uma diferenciação das instituições de saúde voltadas para diferentes ações e diferentes clientelas, as quais se expressam em grande parte em seu caráter privado ou estatal, mas que não se esgotam aí.

Essas estruturas absorvem indiscriminadamente a enfermagem evidentemente como trabalho e trabalhador subsidiário e dependente e como modalidade funcional, sendo sua ação dividida em tarefas e procedimentos.

A enfermagem, não só a brasileira, enquanto ensino formal gerador de enfermeiras de alto padrão, demarcadamente serviu desde o seu nascimento a uma minoria privilegiada. A questão de classe permeia a historia de sua assimilação nos sistemas de saúde institucionalizados. $O$ proletariado fornece, anteriormente, os atendentes de enfermagem, hoje, também auxiliares e técnicos, no início da profissionalização e burguesia fornecia as candidatas para os cursos de enfermeiras, apoiadas na legitimidade desse papel, compatível com o trabalho da mulher fora do lar. A situação de hoje não difere da de muitos anos atrás em termos de autonomia de ação e poder frente à estrutura de serviços, apenas, o que se observa é que ainda se preparam os atendentes, auxiliares e técnicos para as tarefas tidas como predominantemente manuais junto ao paciente. As enfermeiras, por sua vez, agora não são mais recrutadas junto à burguesia, assalariadas e mal pagas, advém hoje das classes média e populares, sendo preparadas para executarem tarefas mais intelectualizadas, supervisāo, ensino e administração.

Assim, a enfermagem que representa o maior contingente de trabalhadores de saúde, ocupa uma posição secundária. As forças de enfermagem desenvolvidas não dispōem nem mesmo de um registro que as identifique como serviço produzido. As estatísticas de saúde a nível de sistema não apontam a enfermagem como executora de atos concretos de saúde que revertem em benefício à população. Nessa estrutura, a enfermagem e as enfermeiras não detém um sistema sintonizado onde, enquanto maioria, interfiram ef etivamente nos niveis decisórios. A realidade é que não detém autonomia nem para a tomada de decisões no seu próprio campo de ação. Não participam da elaboração da maioria da planificaçāo em saúde e não tem acesso a nı́veis hierárquicos de decisão.

Dentre os determiantes que configuram o tipo profissional que se está propondo até aqui, discute-se ainda neste capítulo, o componente "feminino" das tarefas, estabelecido pelos papéis sexuais e responsável pela assimilação de um grande contingente das atendentes de enfermagem, já que, enquanto mulheres apresentam "qualificação inerente" para essas taferas.
Discute-se tamberm neste capítulo dados demográficos da categoria como: sexo, idade, raça, estado civil, origem social, ainda estrutura do emprego, renda, jomada e processo de trabalho, exercício profissional ação e função, culminando com a análise do processo de formação da enfermeira no qual analisamos a reprodução dos estereótipos responsáveis pela manutenção do "status quo" da enfermeira.

Depoimentos de estudantes como: "o nosso curso, por seu contexto e por ser um curso eminentemente feminino, encontra maiores dificuldades de organizar-se e mobilizar-se, caracterizando-se -assim, como um curso despolitizado e descompromissado com seus problemas de classe e da realidade social: ' o estudante de enfermagem é por demais passivo ' quando se deseja promover um debate ou quando se quer um posicionamento $e$, inquieto a ponto de não admitir ficar uns minutos em sala de aula para ouvir um aviso; herança histórica"?

Para GRAMSCI, citado por GADOTTI (1986), "a marca social de uma escola é dada pelo fato de que cada grupo social tem um tipo de escola próprio, destinado a perpetuar nesses grupos uma determinada função tradicional, diretiva ou instrumental. (gritos da autora).

Com essas nuances, a enfermagem tem-se configurado até hoje em ramo derivado e a serviço da medicina. Uma prática subsidiária e subalterna como convém à manutençāo da divisảo social e sexual do trabalho. A definição de seu objeto, sua prática e a construção de um saber autônomo não tem avançado com a aludida cientifização da enfermagem, buscada e acreditada em determinado período apenas pela sua transformação em curso universitário. Engano, não se estrutura um saber autônomo no vácuo de uma medida institucional, burocrática. A divisão e a hierarquia propostas por um diploma, supostamente, conf erem a aura de intelectualidade e o poder do saber institucionalizado, sendo conseqüência de medidas como essa o corporativismo, que então aflora com todas as suas decorrências ao trabalho social.

Resumindo, pode-se afimar que as escolas inculcam em suas alunas a face da enfermagem sempre boa, nobre, sagrada, respeitada, abençoada; a despeito da realidade teimar em apresentar uma face concreta contraditória, problemática, desvalorizada e explorada. A educação não ocorre enquanto ato de mudança e transformação mas sim se perpetua enquanto domesticação ou puro adestramento, servem assim como legitimadores de uma condição subalterna e representam importante papel na produção e reprodução da ideologia dominante.

\section{QUESTÃO DO PODER ...as relaçరes de trabalho - hierarquia e reivindicaçరes.}

É importante que se faça a análise considerando a posição que a enfermeira ocupa em relaçāo ao 
médico no processo de divisão do trabalho. Assim, o técnico comparado ao politécnico (médico e enfermeira) como diz BOURDIEU citado por ORTIZ (1983, p. 113), a luta de classes simbolicas que os opõe, se manifesta na desvalorização técnica de um subordinando-o aos fins práticos. Também outros autores afirmam que essa zona diferencial não é somente o resultado de execução de tarefas técnicas junto ao cliente/paciente; ela se deve, também e fundamentalmente, aos critérios extrínsecos ao trabalho em si; a característica de "status diferenciado", confere a carreira do médico privilégios junto aos seus pares na prática de saúde. Além do conhecimento técnico geral, à carreira médica são adscritas nuances típicas de uma sociedade classista que se manifestam no próprio modo de ser burguês ou pequeno-burguês do m๕dico.

Assim, a grande masca de trabalhadores da saúde (mais de $80 \%$ ) é constiturda pela enfermagem, subsidiando a chamada atividade-fim que é o ato médico. $O$ trabalho da enfermeira e de enfermagem pode ser comparado ao trabalho doméstico, não contabilizado. $O$ que não é contabilizado não tem seu valor econômico ressaltado. $\mathrm{O}$ que não tem seu valor econômico ressaltado, não tem num modelo como nosso, seus direitos respeitados.

Outros enfoque dessa relação reflete, ou mesmo reproduz, a correlação de dominação de uma "'profissão masculina" como a medicina sobre outra "'hegemônicamente feminina". Essa correlação corresponde às relações de poder e autoridade que as mulheres estabelecem fora do âmbito profissional como por exemplo com o pai, com o marido, depois com os filhos homens etc...

Acostumadas a essa hierarquia as mulheres enfermeiras repassam poder numa linha que respeita e hierarquia sexual. Assim se estabelece a seguinte estrutura: médicos (hegemónicamente homens), enfermeiras e auxiliares (hegemónicamente mulheres).

Os profissionais auxiliares, por sua vez, nāo reconhecem a legitimidade da enfermeira tanto no âmbito do conhecimento específico quanto ao nível do exerććcio de liderança de equipe. Já a subordinação ao médico não é questionada. Este é reconhecido e repeitado pelo prestŕgio profissional e pela "figura masculina". Nessa linha é comum ver-se mulheres discriminando a capacidade profissional das proprias mulheres. É comum ouvir-se "prefiro médico do que médica, êles são mais competentes do que elas, inspiram mais confiança e segurança". Ainda, "as mulheres são muito emocionais, para essa profissão tem que ser firme e ter sangue frio" ". Essas constatações determinam dificuldades para as mulheres ao livre exercício profissional (parece que só podem executar o trabalho servil ou cumprir ordens), principalmente quando se trata de se engajar em profissōes construŕdas pela história como masculinas.

A questão mais externa do exercício do poder está relacionada com a capacidade associativa. Fato constatado é que as associaçōes da categoria de caráter voluntária contam com baixíssimo índice de participação.

A participação como ato político estrito, aqui representado intra-categoria pela associação sindical, se dá nos limite da própria ausência de representatividade que a mulher tem nessa esfera em todos os âmbitos.

A escassa participação numérica das enfermeiras decorre supostamente de sua debilidade determinada pela profissão subsidiária e subalterna e sua percepção desser fato. Isso, aliado ao maciço contingente feminino que por si só traz historicamente uma subordinação que, embora varie em grau e expressão, é fato universal na vida social e configura a forma do comportamento dessa categoria.

A participação das enfermeiras em suas entidades é pequena e seus movimentos são comandados por algumas lideranças nacionais e um grupo restrito de vanguarda, configurando a história da enfermagem mais por uma omissão consentida do que por uma atividade manifesta de conquistas.

A representatividade das lutas gerais da sociedade ou não acontece ou se dá de forma tímida, com o receio peculiar ao trauma político do restante da população brasileira, aliado a maior dose de timidez de representatividade das profissōes femininas. A história ate então deflagrada mostra uma desvinculação total das lutas gerais. A questão da mulher e das lutas feministas por exemplo, não foi até o momento objeto de estudo sistemático por parte das organizaçōes representativas da categoria, configurando assim uma perspectiva de total desvinculação ou negação dessa temática. Desvinculação essa de difícil entendimento, já que a questão do papel reservado à mulher na sociedade permeia a própria estrutura da vida associativa dessas entidades.

O dois últimos capítulos analisados nos quais se relata a situação da categoria trazem a possibilidade da análise no confronto do comportamento subordinado das mulheres nos âmbitos público e privado. As contradições, os antagonismos e a marca persistente da subalternidade nas duas esferas, propōe considerações que, longe de serem definitivas, tentarão mostrar que as mulheres continuam a ser as principais vítimas de uma ordem que se mantém e se reforça.

\section{BUSCANDO UMA CONCLUSÃO Mulheres, ainda sombras suaves...}

As bases ideológicas que têm levado a enfermagem e as enfermeiras a "servir" ao capitalismo, refletem as tendências histórica das mulheres a reproduzir a ideologia dominante na sociedade e a assimilação em sua própria conduta dos mitos masculinos a seu respeito.

Esses mitos, na ideologia da sociedade de classes, determinam a condição de mulheres 
fundamentando-se, sociologica e culturalmente, na categoria e no critério do "específico feminino" Essa ideologia do "específico feminino" sustenta e reforça a opressão da mulher, ocultando suas causas. Isso impōe a sustentaçao das regras masculinas tanto nas instituiçōes civis como na famflia, escola, meios de comunicação de massa, partidos políticos e sindicatos como nas instituições religiosas, igrejas, congregações, faculdades teológicas etc...

O discurso da enfermagem ainda está permeado pela incorporação do dogmatismo religioso, pelos discursos teológicos do "específico feminino", reforçado pois pela assimilação profissional das irmãs de caridade. Ainda se tenta buscar argumentos como devotamento, idealismo, altruismo, desprendimento material para justificar a prática profissional sacralizando a dominação e assim ' conseguindo adeptas' .

A enfermeira vive una realidade de dupla opressão. Calcada ainda numa construção mistificada de sua identidade de gênero enquanto mulher, necessita construir uma identidade profissional a nivel do real. Indefinições de papéis a nivel profissional tem sido uma queixa constante. A meu ver, esta indefinição não existe, o que está dada é a negação da contradição entre o discurso da teoria, ou a ideologia teorica e a realidade concreta.

Um quadro construrdo a partir de uma visão idealizada da profissão se contrapōe a um dia a dia que nada tem de postico. A realidade mostra um ramo de trabalho explorado, gerador de tensōes, com carga excessiva de trabalho, mal remunerado e com pouquíssimo poder de barganha frente à classe dominante. Exemplo disso está nos apelos exotéricos no sentido de restringir a propria liberdade de contestação dessas condições de trabalho na área de saúde. Alegações do tipo "os doentes não podem ficar sem assistência; sonegar assistência é crime; onde estão os ideais da profissão?" dentre outros, são evocados quando convém, servindo como disciplinadores ideológicos, como catalisador e neu-، tralizadores das necessidades dos trabalhadores que não podem se comportar como seres humanos dotados de necessidades concretas.

Assim, a condição na qual as mulheres foram assimiladas no campo de trabalho social reflete para as enfermeiras, a divisão sexual do trabalho, a manutenção da subordinação, a característica de prolongamento do trabalho doméstico os componentes de habilidades de concentração, dedicação e paciência, a realidade de uma força de trabalho submissa, serviu e barata. Isso refletido na discriminação a nfvel de tarefas, de salários, das possibilidades de ascensão, da dupla jornada, culminando com a marginalização da vida política.

$O$ entendimento consciente de que respondemos às expectativas de papéis, de que giramos em torno de rígidos padrōes estabelecidos e de uma enganosa representação do espaço privado, é que trará a dimensão e a necessidade de assumirmos um custo social de ruptura com essa condição. A luta das mulheres precisa ser conduzida com a consciência de que a hierarquização, a disciplina, a sujeição sem questionamento, a despolitização, a debilidade associativa das mulheres e o proprio afastamento condicionado estruturalmente do seu "objeto" que é o cliente/paciente, evidenciam a necessidade de manter e reforçar os papéis propostos ao homem e a mulher.

O caráter social histórico dessas tarefas “'femininas' e do trabalho de enfermeira parece estar na raiz de sua subalternidade. $O$ desprestr gio, a subordinação, a subalternidade advêm desse caráter. Nada mais tácito de que servilismo e submissão.

Enquanto profissão de nfvel universitário e enfermagem engendrou uma composição socialmente aceitável para mulher: ' nem só privada, nem só pública' , é boa para mulher, é bom para os filhos dessa mulher, essa é a argumentação. $O$ caráter privado é transferido para o mundo público cristalizando-se nessas "ocupações femininas", que reproduzem o caráter informal do poder da mulher.

Assim, deter um saber nāo hegemónico composto em grande parte por um saber de senso comum que faz parte da própria socializaçāo da mulher, lhes é permitido. E como as mães, as enfermeiras são imbuidas de um ilusorio poder informal e reproduzem um comportamento disciplinar e corporativista no âmbito profissional.

A transformação dessa condição, a conquista da autonomia passa pela necessária relação entre iguais. Romper com a ordem patriarcal requer que pensemos em termos de feminismo e da condição da mulher como alguém que está dentro e náo fora dela. Tomar consciência da opressāo requer que nos identifiquemos como sujeitos dessa opressão, compreendendo todas as nuances e todos os apelos ideológicos de que se reveste. Repensar nosso discurso às vezes ' progressista' , enquanto mulheres, e nossa prática cotidiana conservadora é uma conduta necessária.

Romper com o isolamento, compor uma prática mais solidária entre as mulheres são caminhos indispensáveis para se construir uma nova ordem. Pensar como cidadãs e não somente como filhas, esposas e mães para então nos completarmos como seres sociais e agentes políticos, nos levará à valorização de nós mesmas enquanto pessoa.

A história do capitalismo nos evidencia que não é sob seu signo que conquistaremos uma sociedade de iguais. Também não é diluindo a questão do patriarcalismo no patamar da desigualdade economica que chegaremos a uma sociedade justa.

A exploração da mulher e sua condiçāo secundária na sociedade determina para si e seus filhos, os mais altos niveis de exploração, para os quais merecem que se repensem novas estratégias.

$\mathrm{O}$ ativismo, a presença da mulher nos momentos de enfrentamento, o exercício da crítica consciente, a participação nos movimentos sociais, na 
esfera política formal, são espaços a serem ocupados ef etivamente.

O exercício da cidadania plena é a fonte de ruptura e mudança na condição da mulher. A cisão entre o público e o privado se diluiu no campo do exercício dessa cidadania. Quebrar as amarras requer não apenas se transferir de um campo a outro, mas questionar as estruturas, transformá-las.

O trabalho social por si só não representou a liberdade e a autonomia. Muitos elementos se reforçaram e a mulher assumiu sua culpa ideológica, exercendo a dupla jomada comosendoônus por participar de um mundo que não é seu.

Essa compreensão tem que levar à clareza de que, tanto quanto o trabalho, a reprodução biológica também é social e a divisão sexual de papéis serve à manutenção de um mundo de dominante e dominados. Tendo consciência do caráter indicativo dessas observaçōes ou dessa busca de conclusōes que visam acentuar o verdadeiro problema que, a meu ver, tem mantido as mulheres e as enfermeiras especialmente, trabalhadoras, exploradas e agentes passivos da ação da história.

Destituir nossa prática desse ' legalismo histórico do especifico femfinino' e de tudo que com essa ideologia foi engendrado, reforçado e legitimado pela prática institucional, passa por construirmos instâncias solidárias e críticas que coletivamente representem transformaçōes. Dessa forma construiremos uma nova realidade de sujeito político de destruir a cisão entre as esferas pública e privada enquanto sustentação da dominação.

" Isto aqui é um exercício de liberdade. Quando a mulher começa a lutar pelos direitos como trabalhadora, fica mais fácil lutar por todos os outros' (BRITO, 1985, p.92). Esta frase expressa por uma operária textil ao se referir à sua militância no sindicato da categoria representa, a meu ver, uma das possibilidades concretas de construção desse novo sujeito político capaz de levar num movimento dia- lético, à transformação dos espaços sociais da mulher e à sua libertação.

\section{REFERÊNCIAS BIBLIOGRÁFICAS}

1 ALBORNOZ, S. Na condição de mulher. Santa Cruz do Sul, Faculdades Integradas. 1985. 109p.

2 ALMEIDA, Maria Cecília P. \& ROCHA, Juan S.Y. O saber de Enfermagem e sua dimensão prática. São Paulo, Cortez, 1986. 128p.

3 BIRGIN, Haydée. Quando del poder se trata. Nueva Sociedad, Caracas, 78:100-11, jul./ago. 1985.

4 BRITO, Maria N.C. Sindicato no feminismo:uma luta de formiga. Campinas, Unicamp. 1985.Diss.

5 BRUSCHINI, Cristina A. Mulher e trabalho: uma avaliação da década da mulher 1975 a 1985. In: REUNIÃO ANUAL DE AMPOCS, 9 Águas de São Pedro, 1985.

6 COSTA, Letícia B. Participação da mulher no mercado de trabalho. São Paulo, USP, 1984. 153p.

7 DONNANGELO, Maria Cecília F. Saúde e Sociedade. São Paulo, Duas Cidades, 1976. p.15-68.

8 FOUCAULT, Michell. Microfisica do poder. Rio de Janeiro, Graal, 1985. 295p.

9 GADOTTI, Moacir. Concepçãoa dialética da educação: um estudo introdutório, 4, ed, São Paulo0, Cortez, 1986.

10 ORTIZ, Renato. Pierre Baurdieu, São Paulo, Atica, 1983. $113 p$.

11 ROSALDO, Mechelle Z. \& LAMPHERE, loouise. A mulher, a cultura, a sociedade, Rio de Janeiro, Paz e Terra, 1979, 254p.

12 STOLCKE, Verena et. alii. Trabalho e dominação. Rio de Janeiro, Vozes, 1980 p. 81-117 (Estudos CEBRAP, 26.

13 VELASQUEZ, T. Magdala. Si, tenemos derechos, pero. Nueva Sociedad, Caracas, 78: 93-9, jul./ago. 1985. 